\title{
A PRODUÇÃO NORMATIVA EM SAÚDE COMO UM NOVO CAMPO DE ESTUDO
}

Legislative drafting on health as a new field of study

${ }^{1}$ Consultoria Legislativa, Senado Federal. Brasília/DF, Brasil.

Correspondência: Luiz Carlos Romero. E-mail: romero.luizcarlos@gmail.com.

Recebido em: 18/10/2012. Revisado em: 09/01/2013. Aprovado em: 24/01/2014. 


\section{RESUMO}

Este artigo faz levantamento e análise do aumento no número e na qualidade dos estudos sobre produção normativa em matéria de saúde nos últimos anos, como provável consequência tanto do desenvolvimento do Direito Sanitário em nosso país como do crescimento e da diversificação das atividades de assessoramento e consultoria legislativa em nossas casas legislativas. Conclui-se que houve desenvolvimento recente nesse campo de estudo e na produção científica em nosso meio, caracterizado pelo crescimento do número de estudos e publicações com dois focos principais: o conteúdo normativo das leis e a influência, nos resultados do processo, das regras constitucionais e regimentais que regulam o processo legislativo e favorecem o papel legiferante do Poder Executivo.

\section{Palavras-Chave}

Direito Sanitário; Processo Legislativo; Produção Normativa; Saúde.

\section{ABSTRACT}

This study includes the results of a survey and analysis on the increase in the number and quality of studies on healthcare legislation in recent years. This increase is likely the consequence of both the development of the Health Law in Brazil and the growth and diversification in legal council activities in Brazil's legislative houses. It is concluded that there has been recent development in this field of study and in the scientific production in this area, which is characterized as an increase in the number of studies and publications with two main focuses: the content of laws and the influence, on the results of the legislative process, of the constitutional and procedural laws that regulate the legislative process and reinforce the legislative power of the Executive Branch.

\section{Keywords}

Health; Health Law; Health Legislation; Legislative Process. 


\section{Produção normativa como objeto de estudo}

A produção normativa torna-se objeto de estudo principalmente em razão do fenômeno da proliferação legislativa e do deslocamento dessa função para o Poder Executivo nas sociedades contemporâneas.

São as características desses Estados modernos que justificariam a participação mais decisiva do Poder Executivo na produção normativa, seja intervindo no processo de elaboração das leis, seja exercendo a função de elaborar $o$ ato normativo ${ }^{1}$. Assim, o exercício da competência normativa pelo Executivo consiste em uma releitura do princípio de separação dos poderes, decorrente da evolução sociopolítica da sociedade e do Estado - agora com características neoliberais e reguladoras - e, nesse contexto, aparece como ferramenta indispensável à implementação de políticas públicas específicas ${ }^{2}$. Decorre, também, do dinamismo dos processos tecnológicos e econômicos em setores estratégicos para a economia e os serviços, que exigem intervenção ou regulação estatal e não podem esperar as delongas do processo legislativo para sua regulamentação ${ }^{3}$. Nesse contexto, o poder normativo das agências reguladoras e seus limites tornaram-se temas polêmicos em nosso país ${ }^{4}$, resultando na produção de uma literatura crescente, ainda que mais rara no que se refere à regulação em saúde.

Essa, no entanto, não é a única esfera da atuação normativa do Executivo. O papel normativo exercido pelo Ministério da Saúde na primeira década de construção do Sistema Único de Saúde (SUS), por exemplo, foi estudado por Baptista ${ }^{5}$, que reconheceu nele um padrão de atuação do Estado brasileiro não limitado ao campo da saúde e que o caracterizou pela grande quantidade de normas produzidas (superior a mil portarias por ano) e pelo forte poder de indução na definição da política setorial. Segundo a autora, a organização do SUS e a formulação da política de assistência à saúde decorreram grandemente do exercício do poder normativo pelo Poder Executivo.

Por outro lado, a produção legislativa - isto é, aquela que resulta da atuação do Poder Legislativo - é um objeto de estudo menos frequente. Para Santos ${ }^{6}$, no

\footnotetext{
${ }^{1}$ CLĖVE, Clèmerson Merlin. Atividade Legislativa do Poder Executivo. 2. ed. São Paulo: Ed. Revista dos Tribunais, 2000.

${ }^{2}$ MARTINS, Márcio Sampaio Mesquita. O poder normativo das agências reguladoras como instrumento de implementação de políticas públicas. 2010. Dissertação (Mestrado) - Faculdade de Direito da Universidade Federal do Ceará, 2010.

${ }^{3}$ PACHECO, Carolina Garcia. Agências reguladoras: poder normativo e controle social. Recife: Ed. Nossa Livraria, 2009.

${ }^{4}$ DI PIETRO, Maria Sylvia Zanella. Direito regulatório: temas polêmicos. 2. ed. Belo Horizonte: Fórum, 2004.

${ }^{5}$ BAPTISTA, Tatiana Wargas de Faria. Análise das portarias ministeriais da saúde e reflexões sobre a condução nacional da política de saúde. Cadernos de Saúde Pública, v. 23, n. 3, p. 615-626, mar. 2007. Disponível em: <http://www.scielo.br/pdf/csp/v23n3/20.pdf>. http://dx.doi.org/10.1590/S0102-311X2007000300020.

${ }^{6}$ SANTOS, Fabiano Guilherme Mendes. Clientelismo como escolha racional. In: REIS, Elisa; ALMEIDA, Maria Hermínia T. de; FRY, Peter (Orgs.). Pluralismo, espaço social e pesquisa. São Paulo: Hucitec, 1995. p. 105-137.
} 
Brasil, poucos trabalhos procuram entender o fenômeno da produção legislativa e, na opinião de Vieira ${ }^{7}$, trata-se de um tema carente de bibliografia, em especial quanto ao processo nos âmbitos estadual e municipal. De qualquer forma, os estudos acadêmicos nessa área se fazem mais sob a ótica da Ciência Política do que da do Direito e evidenciam a importância de um ordenamento jurídico coordenado, cujas leis tenham um mínimo de eficácia social e permitam realizar direitos fundamentais e sua tutela jurisdicional.

A ampliação desse campo de estudo poderia, por meio de um melhor entendimento de suas características políticas e jurídicas, contribuir para a redução no número de leis, bem como para a melhoria da qualidade de nossas normas jurídicas e, consequentemente, de seu nível de eficácia ${ }^{8}$ e racionalidade ${ }^{9}$.

Pinheiro defende que a produção legislativa - da mesma forma que a judicial - deve contemplar cinco níveis de racionalidade: (a) linguístico, caracterizado pela clareza e objetividade da norma; (b) jurídico-formal, que contribui para a constituição de um conjunto sem lacunas, sem contradições e sem redundâncias; (c) pragmático, para que as normas produzidas sejam efetivamente obedecidas; (d) teleológico - normas capazes de produzir o resultado a que se destinam; e (e) ético - normas eticamente justificadas. Em sua opinião, "a maior concentração de estudos já elaborados, nas últimas décadas, sobre a produção legislativa e judicial do Direito se situa em nível jurídico-formal e linguístico; muito pouco nos níveis de racionalidade pragmática, teleológica e ética" ${ }^{10}$.

Qualquer que seja a abordagem, os estudos sobre o modo de fazer as leis - inclusive as de saúde - têm se concentrado em duas questões: (a) a escolha do conteúdo normativo e (b) a influência dos procedimentos legislativos, ou da política legislativa, em seus resultados.

\section{Estudos sobre o conteúdo normativo das leis}

Na primeira dessas abordagens - o estudo da substância da produção legislativa -, o principal objeto de pesquisa em nosso meio tem sido o que Santos ${ }^{11}$ denomina de "racionalidade da produção de leis de tipo clientelista".

\footnotetext{
${ }^{7}$ VIEIRA, Bruno Furtado. A produção normativa da Câmara Legislativa do Distrito Federal: um estudo sobre o dever-ser do processo legislativo. Revista Jus Navigandi, Teresina, ano 10, n. 803, 14 set. 2005. Disponível em: <http://jus.com.br/artigos/7291>. Acesso em: 16 set. 2015.

${ }^{8}$ SOARES, Fabiana de Menezes. Teoria da Legislação: formação e conhecimento da lei na idade tecnológica. Porto Alegre: Sergio Antônio Fabris Editor, 2004.

${ }^{9}$ PINHEIRO, José Cláudio. Fundamentos e/ou níveis de racionalidade da produção normativa legislativa e da produção normativa judicial. Novos Estudos Jurídicos, v. 7, n. 15, p. 95-116, dez. 2002. Disponível em: <http://www6.univali.br/seer/index.php/nej/article/view/329>. http://dx.doi.org/10.14210/nej.v7n15.p95-116.

${ }^{10}$ Id. Ibid., p. 109.

${ }^{11}$ SANTOS, Fabiano Guilherme Mendes. Clientelismo como escolha racional, cit., p. 105-137.
} 
Em dois estudos sobre a produção legislativa na Câmara dos Deputados no período de 1959 a 1963 , ambos publicados em $1995^{12}$, esse autor propõe um modelo que permita "investigar os determinantes internos da dinâmica decisória congressual" e, ao mesmo tempo, esclarecer as "características da produção legislativa per se" e "os motivos pelos quais os deputados brasileiros preferem propor e aprovar legislação com certas características e não outras"13.

A principal conclusão desses estudos é que "os deputados, de forma geral, independentemente do partido ao qual estão filiados, preferem produzir legislação de tipo clientelista" e, dessa forma, "a produção legislativa não distingue o comportamento de deputados no que concerne ao aspecto regional ou da representação política no Brasil"14.

Para explicar esses resultados, Santos propõe uma tipologia para as leis e um modelo de análise da produção legislativa - baseado na abordagem da escolha racional e na teoria dos jogos - que passaram a ser empregados em estudos posteriores sobre essa temática. Para a elaboração dessa tipologia, o autor informa apoiar-se em "propostas já consagradas nas áreas de estudos em políticas públicas [...] e de estudos do fenômeno da regulação econômica"15.

As leis são classificadas por ele segundo duas dimensões: a forma e o escopo. A forma refere-se à maneira como uma decisão legislativa concede benefícios ou impõe custos - seja sob a forma de regulamentação de atividades de setores da economia (regulamentos), seja transferindo renda, patrimônio ou recursos ou conferindo benefícios a indivíduos, grupos, regiões, empresas (transferência de recursos). O escopo diz respeito à magnitude do grupo afetado pela lei, que pode ser concentrado (a lei concede privilégios financeiros, patrimoniais ou de status exclusivos a um determinado grupo ou localidade, ou mesmo a indivíduos ou empresas) ou difuso (a lei não alcança grupos específicos, mas tem efeito geral).

O cruzamento dessas duas dimensões dá origem a uma tipologia que contém quatro tipos de leis ou decisões: (a) aquelas que resultam em transferência concentrada de recursos e que, quanto à forma tratam de transferências de recursos e, quanto ao escopo, de benefícios concentrados; (b) aquelas de regulação concentrada, que constituem regulamentos, quanto à forma, e alcançam atividades de grupos específicos, quanto ao conteúdo; (c) aquelas de transferência difusa de recursos que, quanto à forma, são de transferência de recursos, mas, quanto ao escopo, alcançam a população em geral e não grupos específicos; e (d) aquelas de regulação difusa,

\footnotetext{
${ }^{12}$ SANTOS, Fabiano Guilherme Mendes. Clientelismo como escolha racional, cit., Id. Microfundamentos do clientelismo político no Brasil 1959-1963. Dados: revista de ciências sociais, v. 38, n. 3, p. 459-496, 1995.

${ }^{13}$ Id. Microfundamentos do clientelismo político no Brasil 1959-1963, cit., p. 460.

${ }^{14} \mathrm{Id}$. Clientelismo como escolha racional, cit., p. 106.

${ }^{15}$ Id. Ibid., p. 108.
} 
regulamentos que, na forma, cuidam de regras gerais relativas a conflitos distributivos, competitivos e de participação política ${ }^{16}$.

A tipologia pretende, assim, permitir a construção de uma teoria - que Santos denomina de Teoria de Decisões Legislativas - "capaz de determinar os motivos pelos quais os representantes do povo preferem legislar de certa forma e não de outra”, com base no conceito de "custos de oportunidade política", por sua vez definido como "o valor que um político deixa de obter ao propor uma lei de certo tipo e não de outro"17.

Segundo essa teoria, "os deputados levam em consideração não apenas a expectativa de ganho político ou econômico advindo da aprovação de uma lei, mas também o dispêndio de energia e recursos políticos necessários para ver aprovada sua proposição"18. O modelo também assume que "o político busca maximizar suas expectativas de retorno eleitoral e que esse pressuposto é suficiente para derivar proposições consistentes com o comportamento real dos legisladores"19.

A aplicação do modelo à produção legislativa na Câmara dos Deputados no período de 1959 a 1963 permitiu evidenciar que "a produção de leis de tipo clientelista (transferência concentrada de recursos) é predominante, [...] e não distingue deputados de diferentes partidos e regiões" ${ }^{\prime 20}$.

Como tentativa de "oferecer uma explicação positiva para o fenômeno", Santos conclui que seu modelo permite entender porque "as leis cuja proposição encerra custos de oportunidade política marginal reduzidos possuem maior probabilidade de serem produzidas do que leis com outras características" ${ }^{21} \mathrm{e}$, ao mesmo tempo, explicar a existência de "sérios obstáculos à organização de uma ação coletiva que resista à proliferação de leis que transferem recursos públicos para indivíduos, empresas e grupos de interesse ou geográfico, o mesmo não acontecendo para impedir a aprovação de leis que regulem as atividades dos mesmos"22.

Esse modelo teórico, como se verá, tem servido de referência para os estudos sobre a produção legislativa em área social e de saúde, em especial aqueles focados na produção legislativa posterior a 1988.

\section{Estudos sobre o processo legislativo}

As características do processo legislativo são percebidas como um grande determinante dos resultados e da qualidade da produção legislativa, e

\footnotetext{
${ }^{16}$ SANTOS, Fabiano Guilherme Mendes. Clientelismo como escolha racional, cit., p. 105-137.

${ }^{17}$ Id. Ibid., p. 108.

${ }^{18}$ Id. Ibid., p. 111.

${ }^{19}$ Id. Microfundamentos do clientelismo político no Brasil 1959-1963, cit., p. 464.

${ }^{20}$ Id. Clientelismo como escolha racional, cit., p. 133.

${ }^{21}$ Id. Ibid., p. 134.

${ }^{22}$ Id. Microfundamentos do clientelismo político no Brasil 1959-1963, cit., p. 467.
} 
vários estudos foram feitos com vistas a elucidar essa influência. Nessa abordagem, têm sido estudados: a preponderância do Poder Executivo na proposição e aprovação de leis; as questões relativas à iniciativa; a participação popular e o lobby.

A predominância do Executivo na produção legislativa atual é um dos principais tópicos de interesse de estudos sobre produção legislativa, em especial sua ocorrência no Brasil no período posterior a 1988.

Figueiredo e Limongi ${ }^{23}$ estudaram o processo legislativo e a produção legal no Congresso pós-Constituinte, para concluir que "o Executivo pode determinar a agenda e o ritmo da atuação do Congresso" em razão de vários mecanismos institucionais. Ainda que os parlamentares sejam responsáveis pela grande maioria dos projetos de lei apresentados, a maior parte das leis aprovadas corresponde àquelas cuja iniciativa é de competência exclusiva do Executivo (62,4\% no período estudado), o mesmo ocorrendo com as que tratam de matérias em que a competência é de iniciativa comum.

Em nosso meio, o fenômeno recebeu análise acurada em artigo de Figueiredo e Limongi ${ }^{24}$, no qual estudam o desempenho legislativo à luz das relações entre os dois poderes, em decorrência da mudança constitucional.

A Constituição de 88, no que diz respeito ao poder legislativo, aprovou dois conjuntos distintos e, pode-se dizer, contraditórios de medidas. De um lado, os constituintes aprovaram uma série de medidas tendentes a fortalecer o Congresso, recuperando, assim, os poderes subtraídos do Legislativo ao longo do período militar. De outro lado, a Constituição de 88 manteve muitos dos poderes legislativos com os quais o Poder Executivo foi dotado ao longo do período autoritário. Dessa forma não foram revogadas muitas das prerrogativas que permitiram ao Executivo dirigir o processo legislativo durante o regime militar ${ }^{25}$.

Para esses autores, são essas características das relações institucionalizadas entre os poderes, enquanto geradores de normas legais, que permitem ao Poder Executivo, em razão de seus poderes legislativos, comandar o processo legislativo. "O resultado é a atrofia do próprio Legislativo e a predominância do Executivo, principal legislador de jure e de fato"26.

\footnotetext{
${ }^{23}$ FIGUEIREDO, Argelina Cheibub; LIMONGI, Fernando. O processo legislativo e a produção legal no Congresso pós-Constituinte. Novos Estudos Cebrap, n. 38, p. 24-37, mar. 1994.

${ }^{24}$ FIGUEIREDO, Argelina Cheibub; LIMONGI, Fernando. Mudança constitucional, desempenho do Legislativo e consolidação institucional. Revista Brasileira de Ciências Sociais, v. 10, n. 29, p. 175-200, 1995.

${ }^{25}$ Id. Ibid., p. 175.

${ }^{26}$ Id. loc., cit.
} 
Leomar de Souza $a^{27}$ estudou esse fenômeno da migração de parte considerável da função legislativa do Parlamento para o Executivo. Para tanto, tomou como paradigma o instituto da medida provisória e seu "uso abusivo", segundo qual o Poder Executivo vem "exercendo verdadeira competência legislativa ordinária paralela ao Congresso Nacional". O uso excessivo de medidas provisórias, no entanto, não é o único mecanismo responsável pela preponderância do Executivo como legislador: identificam-se, também, a distribuição das competências legislativas feita pela Constituição Federal de $1988^{28}$, o papel do Colégio de Líderes ${ }^{29}$ na determinação das pautas de votação, e as prerrogativas do Poder Executivo de conferir urgência à tramitação das matérias de sua iniciativa e interesse, entre outros.

A participação popular e o lobby também figuram com algum destaque na literatura sobre produção legislativa em geral, mas, em verdade, muito pouco naquela que estuda a produção de leis de saúde ${ }^{30}$.

\section{Para Soares,}

A existência de um sistema de partidos políticos que, em tese, deveriam veicular as forças ideológicas em embate dentro da sociedade não promoveu a abertura de maiores canais de participação popular de modo a permitir o acesso dos cidadãos ao seio dos trabalhos legislativos, à decisão legislativa. $\mathrm{O}$ crescimento dos chamados grupos de pressão (lobbies) dentro dos parlamentos [...] revela que também as formas tradicionais de construção de decisões de natureza legislativa padecem de um hiato democrático e de novos canais de participação popular ${ }^{31}$.

Como se verá, essa é uma questão importante para a produção normativa atual em matéria de saúde, uma vez que "a presença dos lobbies tem o mérito de evidenciar [...] a ausência de espaço relativo à representação de interesses de caráter

\footnotetext{
${ }^{27}$ SOUZA, Leomar Barros Amorim de. A produção normativa do Poder Executivo: medidas provisórias, leis delegadas e regulamentos. Brasília: Brasília Jurídica, 1999. p. 155.

${ }^{28}$ BRASIL. Constituição da República Federativa do Brasil de 1988. Disponível em: <http://www.planalto. gov.br/ccivil_03/constituicao/constituicao.htm>. Acesso em: 16 set. 2015.

${ }^{29}$ O Colégio de Líderes é composto pelos líderes da maioria, da minoria, dos partidos, dos blocos parlamentares e do Governo. É em seu âmbito que é negociada a agenda parlamentar e que são ajustadas as providências necessárias ao processo legislativo. As decisões são tomadas por consenso ou, este não sendo possível, pela maioria absoluta de votos, sendo que o resultado é ponderado pela expressão numérica de cada bancada. Enquanto as votações em plenário, a atuação das comissões, as audiências públicas e o funcionamento das comissões parlamentares de inquérito são, em geral, transmitidas ao vivo por rádio, televisão e internet, as reuniões do Colégio de Líderes costumam ser fechadas, inclusive à imprensa, e suas deliberações nem sempre são tornadas públicas.

${ }^{30}$ LUCCHESE, Geraldo; ROMERO, Luiz Carlos. Representación política y salud: la producción legislativa en salud como construcción social. In: DELDUQUE, Maria Célia et al. (Orgs.) El derecho desde la calle: introducción critica al derecho a la salud. Brasília: FUB, CEAD, 2012. p. 215-224.

${ }^{31}$ SOARES, Fabiana de Menezes. op. cit., p. 141.
} 
coletivo, social ou difuso, enquanto favorece as relações ocultas e ilícitas entre os grupos de pressão e o aparato político"32.

Para Soares ${ }^{33}$, a produção de "leis intrusas" em decorrência da atuação desses grupos de interesse - fenômeno descrito em vários dos estudos atuais sobre a produção legislativa em saúde ${ }^{34}$ - acarreta "problemas no âmbito da coerência interna do sistema normativo e do contexto social no qual atuará".

O fenômeno também está na base da proliferação legislativa, caracterizada pela produção excessiva de leis, pelo crescimento da atividade normativa primária do Executivo e pela baixa qualidade das normas produzidas, "um dos elementos que tipificam a crise do regime representativo" e que resulta na "ocorrência de antinomias no ordenamento jurídico e a incerteza sobre o direito vigente" 35 .

\section{Produção legislativa em saúde como objeto de estudo}

Apesar da intensa produção legislativa em matéria de saúde desencadeada pela Constituição de 1988, ainda é reduzido o número de estudos e reflexões sobre seus determinantes, teores e características. Identifica-se, no entanto, um interesse crescente por esse tema, cuja origem é, preponderantemente, o assessoramento legislativo prestado no âmbito das casas legislativas.

Após a promulgação da Constituição de 1988, começaram a ser produzidos no Brasil estudos que têm, basicamente, dois focos: (a) aqueles que objetivam descrever e explicar a escolha do repertório das novas leis de saúde e (b) aqueles que objetivam identificar e caracterizar a influência do processo legislativo e da atuação dos diferentes atores desse processo sobre o tipo de direito que está sendo assegurado ou regulado.

\section{A escolha do conteúdo das leis de saúde}

Em um primeiro grupo, estão os estudos descritivos sobre o repertório de matérias que são objeto de proposições legislativas e sobre a produção de leis de saúde e as características da proposição, tramitação e aprovação de determinadas matérias, com ênfase no papel dos grupos de interesse e a atuação dos parlamentares segundo sua orientação ideológico-partidária, região de origem e outras características.

\footnotetext{
${ }^{32}$ SOARES, Fabiana de Menezes. op. cit., p. 180.

${ }^{33}$ Id. Ibid., p. 178.

${ }^{34}$ GODOI, Alcinda Maria Machado. Executivo e Legislativo na produção legal em saúde, de 1988 a 2008. 2008. Monografia (Especialização) - Universidade do Legislativo Brasileiro, Universidade Federal de Mato Grosso, 2008; LUCCHESE, Geraldo. A concretização do direito à saúde no Brasil: uma análise da legislação sobre doenças e agravos específicos. 2009. Monografia (Especialização em Direito Sanitário) - Fundação Oswaldo Cruz, Diretoria Regional de Brasília, 2009.

${ }^{35}$ SOARES, Fabiana de Menezes. op. cit., p. 163.
} 
Em nosso estudo da atuação do Senado Federal na área de saúde pública nos anos de 1995 e $1996^{36}$, identificamos o papel relevante da imprensa - em especial da imprensa regional - e de algumas características dos propositores (partido político, região de origem e profissão) na elaboração da agenda legislativa da Casa em relação a matérias de saúde naquela legislatura.

Naquela conjuntura, algumas matérias mobilizaram a atuação parlamentar mais do que outras: drogas, regulamentação de profissões de saúde, controle de doenças e saúde do trabalhador foram objeto de mais ações legislativas do que outras matérias de saúde. Evidenciamos, também, que parlamentares cujas profissões eram de médico, professor e jornalista atuaram mais na elaboração de leis de saúde do que os de outras profissões, bem como os oriundos das regiões Norte e Nordeste, em relação aos representantes das demais regiões. Os senadores de orientação liberal e de direita responderam por $43 \%$ do total de ações do processo legislativo relativo à proposição e à apreciação de leis sobre saúde; contudo, os de orientação socialista e trabalhista tiveram maior participação proporcional ${ }^{37}$. Esses resultados contradizem algumas das hipóteses de Santos $^{38}$.

A Teoria de Decisões Legislativas, de Santos, foi utilizada em três estudos sobre a substancialidade das leis de saúde elaboradas em nossas casas legislativas.

Lemos $^{39}$ estudou a produção legislativa do Congresso brasileiro em relação à distribuição de benefícios sociais no período imediatamente pós-Constituinte (1988-1994). Em uma época de consolidação democrática e de reformas políticas e econômicas, o estudo objetivava esclarecer se e quanto

o padrão (concentrador ou difusor de benefícios) das proposições que tramitam no Congresso Nacional está articulado com a questão do tipo de política pública adequada para se reverter a situação de pobreza e desigualdade social que macula o país. De um ponto de vista mais amplo, essas questões se inserem no problema de fundo, que é o da construção de um Estado de Bem-Estar brasileiro ${ }^{40}$.

${ }^{36}$ ROMERO, Luiz Carlos; CAMARGO, Heloísa Tartarotti; PASSOS, Edilenice L; OTERO, Berenice S; MAGALHÃES, Heloísa Inês; PAULA, Antônio Perreira; PENNA, Sérgio FPO. Atividades do Senado Federal brasileiro na área de saúde pública, 1995-1996. Revista Panamericana de Salud Pública, v. 7, n. 2, p. 69-78, Feb. 2000. Disponível em: <http://www.scielosp.org/pdf/rpsp/v7n2/1240.pdf>. http://dx.doi.org/10.1590/S1020-49892000000200001.

${ }^{37}$ Id. Ibid.

${ }^{38}$ SANTOS, Fabiano Guilherme Mendes. Clientelismo como escolha racional, cit., p. 105-137; Id. Microfundamentos do clientelismo político no Brasil 1959-1963, cit., p. 459-496.

${ }^{39}$ LEMOS, Leany Barreiro de S. O Congresso brasileiro e a distribuição de benefícios sociais no período 1988-1994: uma análise distributivista. Dados: revista de ciências sociais, Rio de Janeiro, v. 44, n. 3, p. 561-605, 2001. Disponível em: <http://www.scielo.br/pdf/dados/v44n3/a04v44n3.pdf>. http://dx.doi.org/10.1590/S0011-52582001000300004.

${ }^{40}$ Id. Ibid. p. 563. 
Diferentemente do que defende aquela teoria, os dados refutaram a hipótese principal de que propostas legislativas concentradoras de benefícios preponderam em relação a propostas que difundem benefícios. No período estudado, houve 59,6\% de propostas deste último tipo, em oposição a 40,4\% de propostas concentradoras de benefícios.

Na busca de explicações para esse fato, a autora aventa que, pelo menos em matérias de educação e saúde e naquela conjuntura, tenham ocorrido uma ou mais das seguintes possibilidades: a maior parte das propostas distributivas não ameaça a reeleição de seus propositores; a preponderância de propostas difusoras está ligada não à racionalidade instrumental, mas a valores compartilhados sobre políticas ideais para a sociedade como um todo; a reeleição depende da percepção do eleitorado sobre o desempenho do parlamentar, e essa percepção não precisa necessariamente estar ligada a um ganho individual, ou ganhos coletivos podem ser mais desejáveis do que ganhos individuais (isto é, a proposta distributiva também teria cunho pragmático); a apresentação de propostas tem pouca influência no cálculo do eleitor, isto é, a avaliação do parlamentar com base em sua atuação é apenas uma das formas de avaliação do eleitorado; como a apresentação de propostas não implica sua aprovação ou implementação, os parlamentares apresentam propostas difusoras para tomar posição e construir um estereótipo que possa corresponder ao ideal de representante do eleitor, mesmo sabendo que as propostas podem não ser aprovadas ou implementadas ${ }^{41}$.

Godoi ${ }^{42}$ também estudou o papel do Executivo e do Legislativo na produção legislativa em saúde nos dez anos que se seguiram à promulgação da Constituição de 1988, utilizando esse mesmo referencial teórico. Entre as principais conclusões de sua tese, está a observação de que "o Legislativo prioriza a ação legislativa em saúde voltada para a adoção de programas e ações de saúde e para questões de natureza simbólica". E identifica também o crescimento no número de leis criando programas de saúde ou ações específicos, supostamente "resultantes de demandas de grupos de interesse, motivadas por situações de dificuldades de acesso e de cobertura do sistema de saúde, problemas que se pretende resolver com a edição de novas leis" e que, a seu ver, podem impactar negativamente o SUS porque "alteram a lista de prioridades de saúde, colocam sob questionamento a eficácia da Lei Orgânica de Saúde”43.

Para a autora, "este é o principal dilema colocado para os formuladores e avaliadores das políticas de saúde: não perder a perspectiva do SUS que se pretende construir, que é o SUS definido constitucionalmente" ${ }^{\text {"44 }}$.

\footnotetext{
${ }^{41}$ LEMOS, Leany Barreiro de S. op. cit.

${ }^{42}$ GODOI, Alcinda Maria Machado. op. cit.

${ }^{43}$ Id. Ibid., p. 58.

${ }^{44}$ Id. Ibid., p. 60.
} 
Bettini ${ }^{45}$ analisou a produção legislativa em saúde da Câmara Legislativa Distrital, no ano de 2008, também empregando esse referencial teórico e obtendo, como resultados, a preponderância da produção de leis de caráter regulatório (na maior parte de iniciativa do Poder Executivo) e a prevalência de leis que fazem transferência difusa de recursos, todas de iniciativa do Legislativo, "portanto leis que contribuíram com algum benefício para a população em geral ou amplos grupos sociais".

Baptista $^{46}$ analisou a produção legislativa em saúde aprovada pelo Congresso Nacional no período de 1990 e 2006, identificando variações importantes nos temas abordados e caracterizando três grandes momentos quanto à matéria das leis produzidas. Esses momentos expressam, na opinião da autora, determinados contextos da política de saúde: "o primeiro, de definição da base institucional do SUS (1990-1994); o segundo, de expansão de políticas técnicas e específicas de saúde, seguidas de uma política de regulação do mercado em saúde (1995-2000); e o terceiro, de retorno de políticas específicas diretamente atreladas a um projeto do Governo Federal (2003-2006)" ${ }^{\prime 47}$.

Dessa forma, pelo menos nos primeiros 15 anos após a Constituição de 1988 entrar em vigor, o contexto político-institucional parece ser um determinante importante na escolha das matérias de proposições legislativas de saúde e, principalmente, a razão principal pela qual certos temas são transformados em lei.

Lucchese ${ }^{48}$ estudou o fenômeno - também identificado por Godoi ${ }^{49}$ e Baptista ${ }^{50}$ - da aprovação de várias leis específicas com o propósito de obrigar o SUS a elaborar políticas para o atendimento de determinadas doenças, agravos ou segmentos populacionais, a fornecer medicamentos e outros insumos terapêuticos, e a realizar ações de prevenção, tratamentos e até procedimentos clínicos, não obstante o mandamento constitucional definir o atendimento integral como diretriz do sistema e a legislação infraconstitucional prever, também, a integralidade e a igualdade da assistência à saúde.

A partir da identificação da produção, desde 1990, dessas "leis específicas" - leis que, na opinião de Baptista $a^{51}$, "segmentam o direito à saúde,

\footnotetext{
${ }^{45}$ BETINI, Giliana. A produção legislativa em saúde na Câmara Distrital no ano de 2008. In: ROMERO, Luiz Carlos; DELDUQUE, Maria Célia. Estudos de Direito Sanitário: a produção normativa em saúde. Brasília: Senado Federal, 2011.

${ }^{46}$ BAPTISTA, Tatiana Wargas de Faria. Análise da produção legislativa em saúde do Congresso Nacional brasileiro (1990-2006). Cadernos de Saúde Pública, v. 26, n. 1, p. 97-109, jan. 2010. Disponível em: <http://www.scielo.br/pdf/csp/v26n1/11.pdf>. http://dx.doi.org/10.1590/S0102-311X2010000100011.

${ }^{47}$ Id. Ibid., p. 105.

${ }^{48}$ LUCCHESE, Geraldo. A concretização do direito à saúde no Brasil: uma análise da legislação sobre doenças e agravos específicos, cit.

${ }^{49} \mathrm{GODOI}$, Alcinda Maria Machado. op. cit.

${ }^{50}$ BAPTISTA, Tatiana Wargas de Faria. Análise da produção legislativa em saúde do Congresso Nacional brasileiro (1990-2006), cit.

${ }^{51}$ Id. Ibid.
} 
discriminando direitos para alguns grupos" - e do número crescente de projetos de lei com essas características apresentados na Câmara dos Deputados entre 2006 e 2008, ele identifica a existência de uma tendência à aprovação de novas leis com essas características e o risco de esse fenômeno produzir um ordenamento jurídico sanitário muito fragmentado, já que grupos de pacientes mais coesos e com mais recursos de organização lutam por leis específicas que contemplem seus interesses, em detrimento de leis de alcance geral ou difuso. Para Lucchese, isso caracteriza uma tendência ao agravamento da desigualdade na atenção à saúde dos brasileiros ou, em outras palavras, uma afronta ao princípio da equidade ${ }^{52}$.

Estudos descritivos sobre a produção normativa relativa a matérias específicas de saúde têm se proliferado nos últimos anos. Foram objetos de publicação recente estudos sobre: a regulamentação da publicidade de tabaco pelo Legislativo Federal ${ }^{53}$; a legislação sobre doação de órgãos e transplantes ${ }^{54}$; a regulamentação da incorporação tecnológica no âmbito do SUS ${ }^{55}$; a regulamentação da saúde suplementar ${ }^{56}$; a regulação da publicidade comercial de produtos de interesse para a saúde ${ }^{57}$; a tramitação da Lei Seca ${ }^{58}$; as proposições tendentes a criar uma Lei de Responsabilidade Sanitária ${ }^{59}$; a regulamentação da Emenda Constitucional n. 29 de $2000^{60}$; e a regulamentação do exercício da profissão médica, conhecida como Lei do Ato Médico ${ }^{61}$.

${ }^{52}$ LUCCHESE, Geraldo. A concretização do direito à saúde no Brasil: uma análise da legislação sobre doenças e agravos específicos, cit.

${ }^{53}$ ROMERO, Luiz Carlos. A regulamentação da publicidade de produtos de tabaco pelo Legislativo Federal. Revista de Informação Legislativa, ano 37, n. 148, p. 303-309, out./dez. 2000. Disponível em: <http://www2.senado.leg.br/bdsf/item/id/647>. Acesso em: 16 set. 2015.

${ }^{54}$ GOMES, Fábio de Barros Correia. Ameaças à equidade na distribuição de órgãos para transplante: uma análise dos critérios legais de acesso. 2007. Dissertação (Mestrado) - Departamento de Serviço Social, Universidade de Brasília, 2007.

${ }^{55}$ MARQUES, Silvia Badim. O princípio constitucional da integralidade de assistência à saúde e o Projeto de Lei $n^{\circ}$ 219/2007: interpretação e aplicabilidade pelo Poder Judiciário. Revista de Direito Sanitário, v. 10, n. 2, p. 64-86, 2009. Disponível em: <http://www.revistas.usp.br/rdisan/article/view/13163>. http://dx.doi.org/10.11606/issn.2316-9044.v10i2p64-86.

${ }^{56}$ ROMERO, Luiz Carlos. A atuação do Congresso Nacional na regulamentação da Saúde Suplementar. Revista de Informação Legislativa, ano 47, n. 186, p. 195-203, abr./jun. 2010. Disponível em: <http://www2.senado. leg.br/bdsf/bitstream/handle/id/198682/000888827.pdf?sequence=1>. Acesso em: 16 set. 2015.

${ }^{57}$ SAIBRO, Ana Luiza Flek. Interesses em jogo na Constituição Brasileira: o conflito entre publicidade comercial e proteção à saúde. In: ROMERO, Luiz Carlos; DELDUQUE, Maria Célia (Orgs.). Estudos de direito sanitário: a produção normativa em saúde. Brasília: Senado Federal, 2011.

${ }^{58}$ MACHADO, Gustavo Silveira. O processo de aprovação da Lei n 11.705 , de 19 de junho de 2008. 2010. Monografia (Especialização em Direito Sanitário) - Fundação Oswaldo Cruz, Diretoria Regional de Brasília, 2010.

${ }^{59}$ ROMERO, Luiz Carlos. A instituição do princípio da responsabilidade sanitária pela via legal. Monografia (Especialização em Direito Sanitário) - Fundação Oswaldo Cruz, Diretoria Regional de Brasília, 2010.

${ }^{6}$ SANTOS, Nelson Rodrigues dos. A regulamentação da Emenda Constitucional 29: dificuldades e perspectivas. In: ROMERO, Luiz Carlos; DELDUQUE, Maria Célia (Orgs.). Estudos de direito sanitário: a produção normativa em saúde. Brasília: Senado Federal, 2011.

${ }^{61}$ MOREIRA JR., Sebastião. Ato médico e a regulamentação do exercício da medicina: processo de discussão no Senado Federal. In: ROMERO, Luiz Carlos; DELDUQUE, Maria Célia (Orgs.). Estudos de direito sanitário: a produção normativa em saúde. Brasília: Senado Federal, 2011. 
Esses estudos descrevem e analisam o tratamento dado pelo parlamento brasileiro a cada uma dessas matérias; a iniciativa das proposições e sua tramitação; a atuação de grupos de interesse; e os resultados em termos da legislação produzida e das razões da dificuldade em se chegar a uma decisão sobre várias dessas matérias. Ainda que basicamente descritivos e com pouca teorização, permitem caracterizar o processo da produção normativa em saúde e o contexto político-institucional no qual ele vem sendo feito.

\section{A influência da política legislativa na produção legislativa em saúde}

Em relação a essa temática, alguns estudos abordaram questões referentes à iniciativa - inclusive a popular - e, em especial, ao papel de cada um dos poderes na proposição e aprovação de leis de saúde.

A atuação de grupos de interesses durante a Assembleia Constituinte foi objeto da tese de Gomes $^{62}$, que descreveu como os representantes do movimento sanitário e suas alianças com o movimento sindical e popular e com os parlamentares progressistas - que ela denominou de "coalizão reformista", favorável às teses da Reforma Sanitária - se contrapuseram ao forte lobby organizado pelo setor empresarial de medicina privada e seus aliados, os parlamentares de centro e de direita - defensores da livre iniciativa da produção de bens e serviços de saúde, do relaxamento dos mecanismos de regulação estatal e contrários à construção de um sistema público estatal de cobertura universal.

Os estudos de Lemos $^{63}$, Godoi ${ }^{64}$, Baptista ${ }^{65}$ e Betini ${ }^{66}$ confirmam a importância das vantagens institucionais e de aspectos organizacionais do processo que favorecem a preponderância do Poder Executivo no processo legislativo, também na área de saúde. No entanto, parece que essa preponderância e, em especial, suas características e resultados refletem, em matérias de saúde, tanto condições institucionais como conjunturais.

Godoi, por exemplo, encontrou que - pelo menos no que diz respeito à produção legislativa das duas casas do Congresso Nacional e na primeira década após a Constituição de 1988 - o maior número de proposições na área de saúde é de iniciativa parlamentar e que a primazia do Executivo em legislar sobre saúde "pode ser observada, se não quantitativamente, pelo menos qualitativamente, uma vez que

\footnotetext{
${ }^{62}$ GOMES, Maria Angélica. Equidade e universalidade do direito à saúde: representação de interesses no Congresso Nacional, 1987-1990. 1996. Dissertação (Mestrado) - Faculdade de Estudos Sociais Aplicados, Universidade de Brasília, 1996.

${ }^{63}$ LEMOS, Leany Barreiro de S. op. cit.

${ }^{64}$ GODOI, Alcinda Maria Machado. op. cit.

${ }^{65}$ BAPTISTA, Tatiana Wargas de Faria. Análise da produção legislativa em saúde do Congresso Nacional brasileiro (1990-2006), cit., p. 97-109.

${ }^{66}$ BETINI, Giliana. op. cit.
} 
as leis de sua lavra alcançam setores ou áreas da política de saúde que, por força de dispositivos constitucionais, estão inacessíveis aos parlamentares pela via legislativa" ${ }^{\text {"67 }}$.

Para Baptista ${ }^{68}$, "no âmbito legislativo, a centralidade do Executivo expressa sua exagerada interferência no processo de produção legal". Essa proeminência é explicada pela autora como decorrência não apenas de disposições constitucionais e regimentais que conferem ao Presidente da República um papel decisivo no processo legislativo - "uma influência incisiva sobre a produção legal"'69 -, mas também da adoção de uma estratégia, por parte do Poder Executivo, que lhe permite dar maior agilidade à tramitação de matérias de seu interesse e ampliar a possibilidade de aprovação.

Essa estratégia é descrita por Baptista como

uma forma de composição do processo decisório no qual o Executivo antecede e negocia, seja com os grupos de interesse reformistas, seja com as corporações, seja com os parlamentares individualmente, seja com a burocracia técnica, quais serão as regras do jogo, garantindo, a priori, a aprovação de suas leis, num pacto muitas vezes pouco transparente da política desenhada e sem registros ${ }^{70}$.

De qualquer forma, Baptista também encontrou padrões diferentes de autoria entre Executivo e Legislativo:

enquanto o primeiro buscou legislar, principalmente, políticas que se referem à administração, regulação e organização setorial, o segundo buscou atender a demandas mais diversificadas e que representam os interesses de grupos específicos, [...] corroborando o que diz a literatura sobre a forma de atuar do Legislativo ${ }^{71}$.

\section{Considerações finais}

A produção legislativa em saúde constitui um novo e promissor campo de estudo e de produção científica, estimulado, por um lado, pelo interesse crescente pelo Direito Sanitário em nosso país e, por outro, pelo crescimento e pela diversificação da atividade de assessoramento e consultoria legislativa em nossas casas legislativas.

Os últimos anos viram crescer o número desses estudos e publicações - ainda que com baixo nível de teorização -, que têm basicamente dois focos: a escolha do conteúdo normativo e a influência, nos seus resultados, das regras constitucionais

\footnotetext{
${ }^{67}$ GODOI, Alcinda Maria Machado. op. cit., p. 58.

${ }^{68}$ BAPTISTA, Tatiana Wargas de Faria. Análise da produção legislativa em saúde do Congresso Nacional brasileiro (1990-2006), cit., p. 97.

${ }^{69}$ Id. Ibid., p. 98.

${ }^{70}$ Id. Ibid. p. 105

${ }^{71}$ Id. Ibid., p. 101-102.
} 
e regimentais que regulam o processo legislativo e favorecem o papel legiferante do Poder Executivo.

Esses estudos permitem compreender a dinâmica do processo legislativo e da definição das agendas legislativas, e evidenciam a importância de um ordenamento jurídico coordenado, cujas leis tenham eficácia social e permitam realizar direitos fundamentais e sua tutela jurisdicional. Dessa forma, a ampliação desse campo de estudo poderia contribuir para a melhoria de qualidade de nossas normas jurídicas e, consequentemente, do nível de racionalidade e eficácia delas.

\section{Referências}

BAPTISTA, Tatiana Wargas de Faria. Análise das portarias ministeriais da saúde e reflexões sobre a condução nacional da política de saúde. Cadernos de Saúde Pública, v. 23, n. 3, p. 615-626, mar. 2007. Disponível em: <http://www.scielo.br/pdf/csp/v23n3/20.pdf>. http://dx.doi.org/10.1590/S0102-311X2007000300020.

- Análise da produção legislativa em saúde do Congresso Nacional brasileiro (1990-2006). Cadernos de Saúde Pública, v. 26, n. 1, p. 97-109, jan. 2010. Disponível em: <http:// www.scielo.br/pdf/csp/v26n1/11.pdf>. http://dx.doi.org/10.1590/S0102-311X2010000100011.

BETINI, Giliana. A produção legislativa em saúde na Câmara Distrital no ano de 2008. In: ROMERO, Luiz Carlos; DELDUQUE, Maria Célia. Estudos de Direito Sanitário: a produção normativa em saúde. Brasília: Senado Federal, 2011.

CLÈVE, Clèmerson Merlin. Atividade Legislativa do Poder Executivo. 2. ed. São Paulo: Ed. Revista dos Tribunais, 2000.

DI PIETRO, Maria Sylvia Zanella. Direito regulatório: temas polêmicos. 2. ed. Belo Horizonte: Fórum, 2004.

FIGUEIREDO, Argelina Cheibub; LIMONGI, Fernando. Mudança constitucional, desempenho do Legislativo e consolidação institucional. Revista Brasileira de Ciências Sociais, v. 10, n. 29 , p. $175-200,1995$.

O processo legislativo e a produção legal no Congresso pós-Constituinte. Novos Estudos Cebrap, n. 38, p. 24-37, mar. 1994.

GODOI, Alcinda Maria Machado. Executivo e Legislativo na produção legal em saúde, de 1988 a 2008. 2008. Monografia (Especialização) - Universidade do Legislativo Brasileiro, Universidade Federal de Mato Grosso, 2008.

GOMES, Fábio de Barros Correia. Ameaças à equidade na distribuição de órgãos para transplante: uma análise dos critérios legais de acesso. 2007. Dissertação (Mestrado) Departamento de Serviço Social, Universidade de Brasília, 2007. 
GOMES, Maria Angélica. Equidade e universalidade do direito à saúde: representação de interesses no Congresso Nacional, 1987-1990. 1996. Dissertação (Mestrado) - Faculdade de Estudos Sociais Aplicados, Universidade de Brasília, 1996.

LEMOS, Leany Barreiro de S. O Congresso brasileiro e a distribuição de benefícios sociais no período 1988-1994: uma análise distributivista. Dados: revista de ciências sociais, Rio de Janeiro, v. 44, n. 3, p. 561-605, 2001. Disponível em: <http://www.scielo.br/pdf/dados/v44n3/ a04v44n3.pdf>. http://dx.doi.org/10.1590/S0011-52582001000300004.

LUCCHESE, Geraldo. A concretização do direito à saúde no Brasil: uma análise da legislação sobre doenças e agravos específicos. 2009. Monografia (Especialização em Direito Sanitário) -Fundação Oswaldo Cruz, Diretoria Regional de Brasília, 2009.

; ROMERO, Luiz Carlos. Representación política y salud: la producción legislativa en salud como construcción social. In: DELDUQUE, Maria Célia et al. (Orgs.) El derecho desde la calle: introducción critica al derecho a la salud. Brasília: FUB, CEAD, 2012. p. 215-224.

MACHADO, Gustavo Silveira. O processo de aprovação da Lei $n^{\circ} 11.705$, de 19 de junho de 2008. 2010. Monografia (Especialização em Direito Sanitário) - Fundação Oswaldo Cruz, Diretoria Regional de Brasília, 2010.

MARQUES, Silvia Badim. O princípio constitucional da integralidade de assistência à saúde e o Projeto de Lei no 219/2007: interpretação e aplicabilidade pelo Poder Judiciário. Revista de Direito Sanitário, v. 10, n. 2, p. 64-86, 2009. Disponível em: <http://www.revistas.usp.br/ rdisan/article/view/13163>. http://dx.doi.org/10.11606/issn.2316-9044.v10i2p64-86.

MARTINS, Márcio Sampaio Mesquita. O poder normativo das agências reguladoras como instrumento de implementação de políticas públicas. 2010. Dissertação (Mestrado) - Faculdade de Direito da Universidade Federal do Ceará, 2010.

MOREIRA JR., Sebastião. Ato médico e a regulamentação do exercício da medicina: processo de discussão no Senado Federal. In: ROMERO, Luiz Carlos; DELDUQUE, Maria Célia (Orgs.). Estudos de direito sanitário: a produção normativa em saúde. Brasília: Senado Federal, 2011.

PACHECO, Carolina Garcia. Agências reguladoras: poder normativo e controle social. Recife: Ed. Nossa Livraria, 2009.

PINHEIRO, José Cláudio. Fundamentos e/ou níveis de racionalidade da produção normativa legislativa e da produção normativa judicial. Novos Estudos Jurídicos, v. 7, n. 15, p. 95-116, dez. 2002. Disponível em: <http://www6.univali.br/seer/index.php/nej/article/view/329>. http://dx.doi.org/10.14210/nej.v7n15.p95-116.

ROMERO, Luiz Carlos. A atuação do Congresso Nacional na regulamentação da Saúde Suplementar. Revista de Informação Legislativa, ano 47, n. 186, p. 195-203, abr./jun. 2010. Disponível em: $<$ http://www2.senado.leg.br/bdsf/bitstream/handle/id/198682/000888827.pdf?sequence=1 $>$.

. A instituição do princípio da responsabilidade sanitária pela via legal. Monografia (Especialização em Direito Sanitário) - Fundação Oswaldo Cruz, Diretoria Regional de Brasília, 2010. 
ROMERO, Luiz Carlos. A regulamentação da publicidade de produtos de tabaco pelo Legislativo Federal. Revista de Informação Legislativa, ano 37, n. 148, p. 303-309, out./dez. 2000. Disponível em: <http://www2.senado.leg.br/bdsf/item/id/647>. Acesso em: 16 set. 2015.

; CAMARGO, Heloísa Tartarotti; PASSOS, Edilenice L; OTERO, Berenice S; MAGALHÃES, Heloísa Inês; PAULA, Antônio Perreira; PENNA, Sérgio FPO. Atividades do Senado Federal brasileiro na área de saúde pública, 1995-1996. Revista Panamericana de Salud Pública, v. 7, n. 2, p. 69-78, Feb. 2000. Disponível em: <http://www.scielosp.org/pdf/ rpsp/v7n2/1240.pdf>. http://dx.doi.org/10.1590/S1020-49892000000200001.

SAIBRO, Ana Luiza Flek. Interesses em jogo na Constituição Brasileira: o conflito entre publicidade comercial e proteção à saúde. In: ROMERO, Luiz Carlos; DELDUQUE, Maria Célia (Orgs.). Estudos de direito sanitário: a produção normativa em saúde. Brasília: Senado Federal, 2011.

SANTOS, Fabiano Guilherme Mendes. Clientelismo como escolha racional. In: REIS, Elisa; ALMEIDA, Maria Hermínia T. de; FRY, Peter (Orgs.). Pluralismo, espaço social e pesquisa. São Paulo: Hucitec, 1995. p. 105-137.

Microfundamentos do clientelismo político no Brasil 1959-1963. Dados: revista de ciências sociais, v. 38, n. 3, p. 459-496, 1995.

SANTOS, Nelson Rodrigues dos. A regulamentação da Emenda Constitucional 29: dificuldades e perspectivas. In: ROMERO, Luiz Carlos; DELDUQUE, Maria Célia (Orgs.). Estudos de direito sanitário: a produção normativa em saúde. Brasília: Senado Federal, 2011.

SOARES, Fabiana de Menezes. Teoria da Legislação: formação e conhecimento da lei na idade tecnológica. Porto Alegre: Sergio Antônio Fabris Editor, 2004.

SOUZA, Leomar Barros Amorim de. A produção normativa do Poder Executivo: medidas provisórias, leis delegadas e regulamentos. Brasília: Brasília Jurídica, 1999.

VIEIRA, Bruno Furtado. A produção normativa da Câmara Legislativa do Distrito Federal: um estudo sobre o dever-ser do processo legislativo. Revista Jus Navigandi, Teresina, ano 10, n. 803, 14 set. 2005. Disponível em: <http://jus.com.br/artigos/7291>. Acesso em: 16 set. 2015.

Luiz Carlos Romero - Mestre em Saúde Coletiva pela Universidade de Brasília; especialista em Direito Sanitário pela Fundação Oswaldo Cruz; especialista em Saúde Pública pela Faculdade de Saúde Pública da Universidade de São Paulo; graduado em Medicina pela Universidade Federal do Rio Grande do Sul. Consultor Legislativo do Senado Federal. Brasília/DF, Brasil. E-mail: romero.luizcarlos@gmail.com. 